\title{
The Chromosomes of a Triploid Oenothera Hybrid.
}

\author{
$\mathrm{BY}$ \\ R. RUGGLES GATES, Ph.D., F.L.S., \\ Professor of Botany, University of London (King's College). \\ With Plate XII.
}

$\mathrm{T}$ I9I 2 crosses were made at the John Innes Horticultural Institution between Oenothera rubricalyx and Oe.gigas. The Oe. rubricalyx parent, having I 4 chromosomes, was descended in the third generation from the original mutant which occurred in 1907 . The Oe. gigas parent belonged to the second generation from seeds obtained from the Palermo Botanical Garden under the name of Oe. cognata. This race was identical in character, chromosome number (28), and variability with the gigas mutant of de Vries's cultures, and it doubtless represented an independent origin of the tetraploid condition. A further account of this race was published elsewhere (Gates; 1913).

From the cross Oe. rubricalyx $\times$ gigas 199 seeds were obtained in one capsule. They were sown in 19I3 at Rothamsted, but only one plant developed. The rosette leaves were large, broad, and crinkled like those of gigas, and the midribs were green below, not red as in mubricalyx. The plant grew very large, stout and taller than the parent forms, as is usual in triploid hybrids. The leaves stood out from the stem and the flowers were 'very large', the buds showing the red sepals and hypanthium of rubricalyx, but conspicuously pale in colour. The leaves were less crinkled than in gigas. Thus in this hybrid with $2 x$ chromosomes from the male parent gigas and $x$ from the female parent rubricalyx, the usually dominant red pigmentation character was so diluted as to be invisible on the rosette leaves and pale on the buds. The foliage was intermediate, but more like that of gigas. Examination of the pollen showed that 'bad' grains and 'good' grains were in the ratio of about $4: \mathrm{I}$. The apparently functional grains were four-lobed (as in gigas) or three-lobed in the ratio of about $2: \mathrm{I}$. The lobing of Oenothera pollen grains has been discussed elsewhere (Gates,

[Annals of Botany, Vo1. XXXVII. No. CXLVIII. October, 1923.] 
I9I5, p. 212), and it was shown that grains with less than the full diploid number of chromosomes may still be four-lobed. Probably in this plant the four-lobed grains, which numbered about 12 per cent. of all the pollen grains, had not less than Io chromosomes. Further reference will be made to this point later.

At the end of the season this plant was potted and placed in a greenhouse. Its main stem died and was cut down. Then a number of short side shoots developed from the base bearing rosette leaves. These rosettes were mostly like gigas with broad-pointed crinkled leaves. One shoot, however, was quite different, nearer Lamarckiana, with leaves pointed and nearly smooth. Another shoot was intermediate in character between these. Unfortunately no photograph was obtained, and although cuttings were attempted the plant finally died and was lost. The variation in the character of the leaves on different shoots was no doubt due to the loss of certain chromosomes from their growing points. This undoubtedly occurs, as in the meiotic divisions, through the dropping out of certain chromosomes in the cytoplasm, a process which may be expected to take place when a plant with an unbalanced chromosome number is placed in unusual conditions.

Cytological material was collected in 1913 for a study of the meiotic divisions in this plant, but the embedded paraffin material was laid aside and was only sectioned last year. I am indebted to Miss E. M. Rees, B.Sc., for making the preparations (stained in iron-haematoxylin), and to Mrs. N. Ferguson, B.Sc., for the careful drawings. Fig. I, Pl. XII, is a side view of the heterotypic spindle in the pollen mother-cell. It shows 2I chromosomes somewhat scattered along the spindle, as is usual in many Oenotheras. The other illustrations have been selected to show how the $2 \mathrm{I}$ chromosomes are distributed in the reduction divisions and how the number gradually drops down, through the omission of chromosomes from the daughter nuclei in both divisions, until many of the pollen nuclei receive only 7 .

Fig. 2 is a homotypic metaphase showing Io chromosomes in the righthand group and probably II in the other. Usually this is the segregation which takes place on the heterotypic spindle, 10 chromosomes entering one daughter nucleus and I I the other. Chromosomes may however be left behind on the heterotypic spindle. Thus in Fig. 3 we have a homotypic anaphase with 18 chromosomes on the left-hand spindle and 20 on the right. Under the microscope these are clearly in two separate groups of 9 and Io respectively, although the groups necessarily overlap somewhat in the drawing, since the spindles were obliquely placed. Hence 9 split chromosomes have separated normally on the left-hand spindle and to on the right. This means that a total of I 9 chromosomes only is now present, and hence the other two must have been left behind on the heterotypic spindle and disintegrated. Similar conditions have been observed in other pollen mothercells. 
Fig. 4 shows another homotypic anaphase in which more chromosomes have been lost, for there are only 8 pairs of separating chromosomes on the left-hand spindle and 7 pairs on the right. Hence the remaining 6 whole chromosomes must have been left out of the daughter nuclei on the heterotypic spindle.

In Fig. 5 a homotypic spindle is in telophase, with 7 chromosomes at either pole and an eighth divided chromosome remaining behind. Only 8 chromosomes reached the daughter nucleus, which is here dividing. As the number of chromosomes on the other homotypic spindle is unknown, it is impossible to say how many of the other I 3 chromosomes reached the opposite pole of the heterotypic spindle. Fig. 6 shows a homotypic spindle in which 8 chromosomes have reached either pole and a ninth split chromosome is disintegrating on the spindle. Probably in this mother-cell at least one chromosome was lost from this end of the heterotypic spindle. Fig. 7 represents a not infrequent condition in which only 7 chromosomes have arrived at the poles of a homotypic spindle, the eighth disintegrating.

These figures show that a varying number of chromosomes may be lost during either of the reduction divisions in this triploid hybrid. Occasionally all the chromosomes may reach the daughter nuclei in the heterotypic mitosis, but usually one, two, or more unpaired chromosomes are left behind to disintegrate. All the chromosomes which reach the daughter nuclei in the heterotypic division apparently undergo a split. When the homotypic spindles are formed and these split chromosomes separate, a certain number of them may again be left behind, so that the number of chromosomes ultimately reaching the four daughter nuclei is usually only 7 or 8 .

In an early paper (Gates, 1909) on Oenothera lata $\times$ gigas I showed how the 2 I chromosomes usually separate IO-I I on the heterotypic spindle, but sometimes 9-12.1 Apparently in that material all the chromosomes usually reached the two daughter nuclei. The chromosome numbers in interkinesis therefore ranged only from 9 to 12 , and this entirely owing to the sometimes irregular chromosome distributions. In the present hybrid Oenothera rubricaly $x \times$ gigas, however, there is evidence that from one to six chromosomes are frequently lost on the heterotypic spindle, since the numbers on the homotypic spindles are frequently only 8 , 9, or Io.

That similar conditions occur in the pollen formation of other triploid Oenotheras is indicated by recent results of van Overeem (1920), to which brief reference may be made. From Oe. Lamarckiana mut. semigigas (2I chromosomes) crossed with Lamarckiana he obtained plants as follows: $\mathrm{I} \times 14,9 \times \mathrm{I} 5,4 \times 16,2 \times 17,2 \times 18,1 \times 20$, and $\mathrm{I} \times 2 \mathrm{I}$ chromosomes; from semigigas $\times$ gigas $1 \times 21,2 \times 22,12 \times 23,21 \times 24,25 \times 25,19 \times 26,6 \times 27$, and $\mathrm{I} \times 28$. Oe. biennis semigigas $\times$ Lamarckiana gigas gave corresponding

1 These results have recently been confirmed by van Overeem (1922) in an important paper dealing with various triploid and other forms. 
results. The most common chromosome number was therefore 24,25 , or 26 , when gigas was the pollen parent. The reciprocal, Lamarckiana gigas $\times$ semigigas, gave $3 \times 2 \mathrm{I}, \mathrm{I} \times 22, \mathrm{I} \times 27,10 \times 28$, and $3 \times 29$. Hence 28 chromosomes was the commonest number when gigas was seed parent. The exact manner of origin of the large number of 28's and 29's in gigas $x$ semigigas is perhaps uncertain. These results confirm the writer's early observations that in triploid forms the segregation of chromosomes is usually IO-II, but occasionally 9-I2. They indicate further that the segregation may be occasionally $8-\mathrm{I} 3$ and rarely even $7-\mathrm{I} 4$.

From Oe. biennis semigigas $\times$ biennis van Overeem obtained a somewhat narrower range of variation. There were $4 \mathrm{I}$ plants with $\mathrm{I} 4$ chromosomes, 26 (albinervis) with I5, and 4 with 16 . In biennis semigigas $\times$ gigas, on the other hand, the chromosome numbers were $2 \mathrm{I}, 22,23,24,25,26,27,28$, and one plant with $3^{6}$, while Lamarckiana gigas $\times$ biennis semigigas gave 33 plants with 28 chromosomes, 2 with 29, and 6 undetermined. Van Overeem suggests with probability that the plant with 36 chromosomes arose from an egg cell of biennis semigigas having 8 chromosomes uniting with a pollen grain of gigas having 28. That such a pollen nucleus may arise in gigas has already been shown (Gates, 1915, Fig. 73 f.).

In a plant from Oe. gigas $\times$ lata rubricalyx which had 22 chromosomes (Gates, 1915, p. I89) I showed that the chromosome segregation in the pollen heterotype was usually IO-12, but other daughter nuclei were observed having II, I 3 , and 9 chromosomes, as well as $6 \frac{1}{2}$ and $9 \frac{1}{2}$, which points to the production of a range of new numbers in the next generation.

The present study of the reduction divisions in the pollen of Oe. rubricalyx $\times$ gigas helps to make clear the chromosome behaviour of triploid forms, and explains the origin of the wide range of chromosome numbers found in their offspring.

\section{SUMMARY.}

This paper deals with the distribution of the chromosomes in the microspore meiosis of a triploid hybrid, Oe. rubricaly $x \times$ gigas. It confirms earlier results with similar triploid hybrids and further explains how the variety of chromosome numbers found in the second generation of such hybrids arises.

In the heterotypic mitosis the chromosome distribution is usually IO-I I, but from $\mathrm{s}$ to 6 chromosomes may be left out of the daughter nuclei. This is shown by the chromosome numbers on the homotypic spindles, which may be $\mathbf{I}, 10,9,8$, or 7 , and usually differ in the two homotypic spindles of a cell. Cases occur where these two spindles have $10+1 \mathrm{I}, 9+10$, or $8+$ 7. All the chromosomes regularly split and separate on the homotypic spindles, but certain split chromosomes frequently lag behind and are left out of the daughter nuclei, as on the heterotypic spindle. 
Gates.-The Chromosomes of a Triploid Oenothera Hybrid. 569

Thus pollen grains will be formed having every chromosome number between II or I 2 and 7. As pairs of tetrad nuclei usually have the same chromosome number, aberrant forms should be looked for in pairs in the next generation.

These experiments were aided by grants from the Royal Society and the British Association.

\section{LITERATURE CITED.}

Gates, R. Ruggles (1909): The Behaviour of the Chromosomes in Oenothera lata $\times$ gigas. Bot. Gaz., xlviii. I 79-99, Pls. I 2-J4.

(1913): Tetraploid Mutants and Chromosome Mechanisms. Biol. Centralb., xxxiii. 92-9, I 3 3-50, Fig. 7 .

(1915): The Mutation Factor in Evolution, with Particular Reference to Oenothera. London, Macmillan, pp. 353, Figs. 114.

van Overeem, Caspar (1920): Über Formen mit abweichender Chromosomenzahl bei Oenothera. Dissertation. Beihefte z. Bot. Centralblatt, xxxviii, pp. 47 , Pls. 6.

(1922): Same title. Ibid., xxxix, pp. I-8o, Pls. I 5.

\section{EXPLANATION OF PLATE XII.}

Illustrating Professor Gates's paper on the Chromosomes of a Triploid Oenothera Hybrid.

All figures were drawn with a $\frac{1}{12}$ in. Koristka immersion lens N A. I.3O and compensating ocular $\mathrm{I}_{2}$, tube length $15^{2} \mathrm{~mm}$., and reduced one-fourth in reproduction, giving a magnification of 2,250 diameters.

Fig. I. Heterotypic anaphase in a pollen mother-cell of Oe. rubricalyx $\times$ gigas, showing twenty-one chromosomes somewhat scattered.

Fig. 2. Homotypic metaphase, showing ten chromosomes on right-hand spindle and probably eleven on left-hand.

Fig. 3. Homotypic anaphase, showing ten split chromosomes separating on right-hand spindle and nine on left-hand. The other two chromosomes were evidently lost on the heterotypic spindle.

Fig. 4. Homotypic anaphase, showing the two daughter groups of eight chromosomes on the left-hand spindle and two groups of seven on the right-hand. The remaining six chromosomes must have been lost in the heterotypic mitosis.

Fig. 5. Homotypic telophase, showing seven chromosomes entering each daughter nucleus, and an eighth divided but left behind.

Fig. 6. Homotypic telophase, showing eight chromosomes at either end of spindle and a ninth split chromosome disintegrating on the spindle.

Fig. 7. Homotypic telophase, showing seven chromosomes at each pole of the spindle, the eighth divided but left behind. 
Annals of Botany,
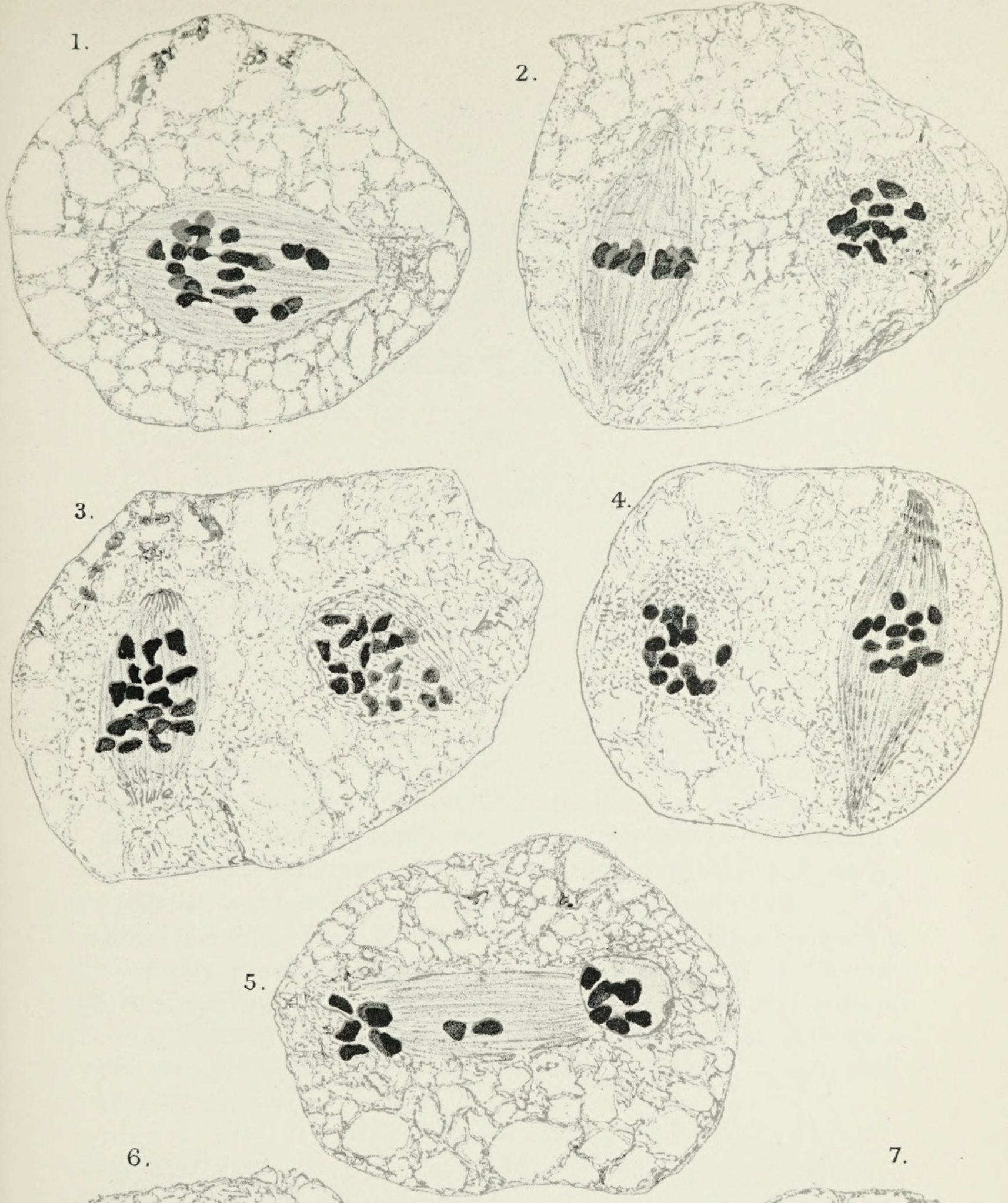

7.

6.

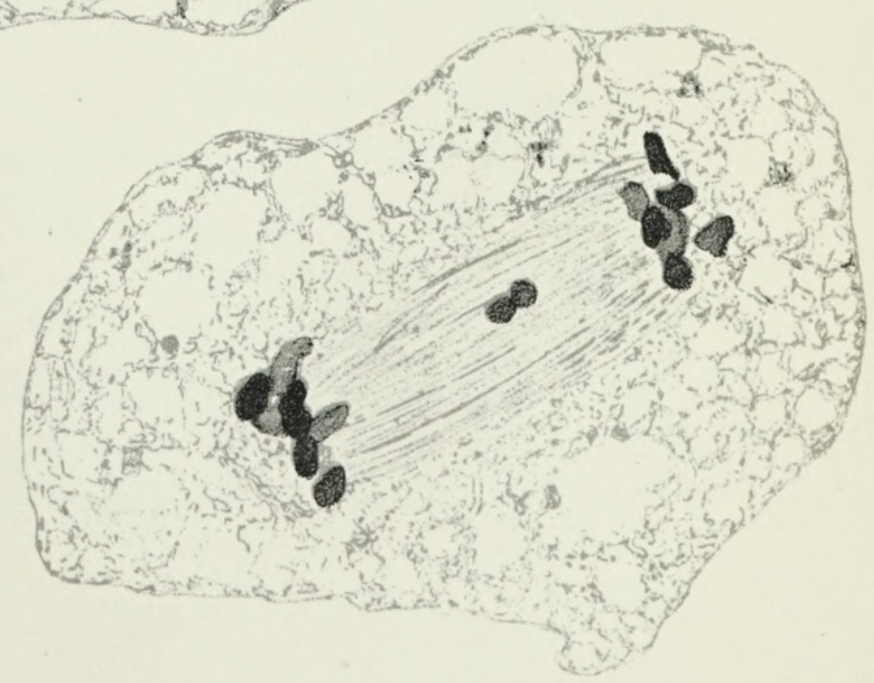




\section{$2 \mathrm{BHL}$ Biodiversity Heritage Library}

Gates, R. Ruggles. 1923. "The chromosomes of a triploid Oenothera hybrid." Annals of botany 37, 565-569.

https://doi.org/10.1093/oxfordjournals.aob.a089867.

View This Item Online: https://www.biodiversitylibrary.org/item/270686

DOI: https://doi.org/10.1093/oxfordjournals.aob.a089867

Permalink: https://www.biodiversitylibrary.org/partpdf/319103

\section{Holding Institution}

New York Botanical Garden, LuEsther T. Mertz Library

\section{Sponsored by}

BHL-SIL-FEDLINK

\section{Copyright \& Reuse}

Copyright Status: Public domain. The BHL considers that this work is no longer under copyright protection.

This document was created from content at the Biodiversity Heritage Library, the world's largest open access digital library for biodiversity literature and archives. Visit BHL at https://www.biodiversitylibrary.org. 